\title{
Prosodic organization of English folk riddles and the mechanism of their decoding
}

\author{
Larysa Taranenko \\ National Technical University of Ukraine "Kyiv Polytechnic Institute", Ukraine
}

\begin{abstract}
The paper advances a cognitive model representing a creative mechanism of riddle decoding by its recipient, which serves as a theoretical and methodological ground for the experimental phonetic study of prosodic means that organize the text of a riddle. Within the process of cognitive model formation the author performs a conceptual analysis of the riddle compositional structure, presented as a systemic algorithmic scheme. It is confirmed that a characteristic feature of a folk riddle is its division into two elements: the first one is the description of an object, further differentiated into "topic" and "commentary", while the second one is the riddle answer, or solution, generated directly in the recipient's mind as a result of his/her mental activities. The carried out auditory analysis proves that such a limitation of the riddle's structure is compensated by a set of prosodic means and their specific interaction, which trigger creative and cognitive processes in the recipient's mind aimed at searching for the riddle solution.
\end{abstract}

Keywords: English folk riddle, structural elements, scheme, decoding, cognitive model, creative mechanism, prosodic means, recipient

\section{Introduction}

The results of our previous studies (Taranenko 2013: 168) confirmed that a characteristic feature of a folk riddle is its clear division into two parts, reproduced by different individuals. The first part is the content of a riddle, which contains a description of the object, while the second one is the riddle answer, or solution, formed directly in the recipient's mind as a result of his/her mental activities. It was assumed that such a limitation of the riddle's structure should be compensated by prosodic means' interaction, which triggers creative and cognitive processes in the recipient's mind aimed at searching for the riddle solution.

Considering these ideas, in the present paper we have undertaken a substantiation of a cognitive model representing a creative mechanism of a riddle decoding, which serves as a theoretical and methodological ground for the experimental phonetic study of the prosodic means that organize the text of a riddle. 
To solve the outlined problems we have chosen the following sequence of methodological actions. It was rational within the first step to come up with a certain systemic scheme, or a pattern of the riddle structural components. The second step presupposed the formation of a cognitive model, representing a creative mechanism of riddle decoding by a recipient. Within the third step, on the basis of auditory analysis of English folk riddles, we described the characteristics of their prosodic organization that influence the recipient's search for the riddle solution as well as substantiated invariant prosodic features typical of the riddle structural elements.

\section{Theoretical and methodological background of the research}

\subsection{Defining the characteristic features of the riddle as a folk genre}

The analysis of theoretical sources has shown that researchers come across certain contradictions while giving an explicit definition of the genre of a riddle. The earliest explanation of the riddle as a metaphor is related to the work of Aristotle (2000: 117), who was probably the first to define the riddle. In the classical tradition scholars largely follow the definition proposed by G. Paris, who designated the riddle as a metaphor or a group of metaphors, which are not typical of everyday use and whose explanation is not obvious (Tupper 1910: xiii).

It is believed that the greatest contribution to the study of riddle was made by Taylor (1943), who offered a classification of English folk riddles and defined the riddle as the one that compares two completely different objects (Georges and Dundes 1963: 111). In this regard, some researchers attribute the origin of riddles to the "conventionally codified speech" (Anikin 1957: 56), or secret speech, used to represent the world as certain concepts and images when people were unable to speak openly (Panasenko 2009: 382).

Throughout the time the riddle was considered by folklorists from different standpoints, including the study of its evolution as a genre (Kaivola-Bregenhøj and du Bois 2001), its correlation with other small form folklore texts (Abrahams 1968, Dundes 1975, KaivolaBregenhøj and du Bois 2001, Green and Pepicello 1986, de Caro 1986, Permyakov 1975: 260), the emergence of riddle as a result of transformation of ancient mythological texts (Ivanov and Toporov 1975: 70), the difference between folk and literary riddles (Tupper 1910: xvixviii, Taylor 1943), etc. Within a linguistic approach the attention was given to the study of the riddle structure (Georges and Dundes 1963), its formal (Taylor 1943) and functional features (Permyakov 1975: 254-257, de Caro 1986) as well as to the language means of its organization (Beuchat 1965: 196-202, Green and Pepicello 1980, Köngäs-Maranda 1971, Köngäs-Maranda 1971b) and cognitive mechanisms of the riddle denotation (Selivanova 2005).

Unfortunately, among the scholars there is no unanimous agreement on the status of a riddle as a folk genre. The debates unfold around the ideas whether this status should be based on the structural elements of the riddle or its functions, the sphere of usage or speech context in which it appears, etc. Thus, in terms of its semantic plane the riddle is defined as a 
text, whose denotative element is represented by a particular object, not named in the text of a riddle (Levin 1973: 166). Within a pragmatic description the riddle is viewed as a genre that has the "question-answer" structure and a multifunctional communicative use as well as combines in itself features of both an utterance and a text. Besides, it is noted that the leading cognitive-pragmatic functions of a riddle are logical and image-creative ones, i.e. the formation in the speakers' minds of logical clichés filled with images from the traditional culture in their "metaphorically creative" role (Semenenko 2011: 134). In other works (Fylyppov 2000: 2) the riddle is considered as a specific discursive formation or as a standardized dialogue represented according to definite rules and principles.

Another idea, interesting for our consideration, was expressed in the paper (KaivolaBregenhøj and du Bois 2001: 165), where the authors point to the necessity of creating an international index of riddles, similar to the known index of fairy tales (Aarne 1961, Thompson 1955). We believe that the solution of this issue can contribute to our search for a comprehensive unified system of functional and structural characteristics of all small form folk texts.

The consideration of functional features of the text of a riddle can be based on Lotman's postulate (1992: 150) that within the culture, texts perform two main functions: an adequate transmission of meanings and generation of new meanings. In terms of a riddle the majority of scholars indisputably recognize a didactic function as its primary sociocultural goal (Alefyrenko and Semenenko 2010: 178, Semenenko 2011: 132, Gimbutas 2004: 11). At the same time, there is no doubt as to the multifunctional nature of a folk riddle, quite explicitly overviewed in the paper (Semenenko 2011: 130-133), where the author named the following functions of a riddle: cognitive, modelling, image-creative, image-regulatory, ritual, entertaining, and others. Even though the description of riddle functions, presented in this paper, is not, in our opinion, logically structured, it gives us a sufficient terminological material for the clarification of the nature of the riddle communicative sub-functions, participating in the realization of its general didactic function.

Thus, as a result of the carried out analysis we can inevitably come to the conclusion that the system of riddle functions acquires the following hierarchical subordination: general didactic function $\rightarrow$ creative-and-instructive pragmatic orientation $\rightarrow$ entertaining-andtraining function.

Considering this, we can formulate a generalized definition of the riddle as a genre. We define the riddle as a specific folk genre, whose text, having a creative-and-instructive pragmatic orientation, performs an entertaining-and-training functional role, realized on the basis of an associative-and-creative mechanism of reconsideration of knowledge, existing in the recipient's mind.

This definition as well as a hierarchical system of the riddle functional characteristics will serve as a theoretical basis for accomplishing an adequate scientific description of prosodic means' interaction in the riddle actualization. 


\subsection{Results of the conceptual analysis of the riddle compositional structure}

The circle of issues comprising the problem of the riddle prosodic organization as a complex phenomenon of oral folklore also includes the study of the riddle structural composition. The solution of this issue was realized by means of the content analysis of the riddle plot elements and formation of its typical algorithmic structural pattern.

According to a number of linguists (Georges and Dundes 1963: 111, Abrahams and Dundes 1982: 130), the most comprehensive description of the riddle structural organization is contained in the work by Petsch (1899), who distinguished its five elements: 1) introductory frame element; 2) denominative kernel element; 3) descriptive kernel element; 4) block element; and 5) concluding frame element. The author himself admits that riddles containing all five elements are extremely rare, and remarks that one or both of the frame elements are usually absent. He also observes that the block element is absent even more often. Therefore, we tend to share the views expressed by Georges and Dundes (1963: 111) that the mentioned structural composition of a riddle cannot be widely applied. We also support their statements (ibid.: 113) that only two of Petsch's five elements are structural ones - the descriptive kernel element and the block element, while the opening and closing elements, or formulas, are rather stylistic devices whose presence is optional and does not affect the overall structure of the riddle.

There is also a famous view on the riddle structure by Taylor (1943: 130), who proposed the division of its structure into two descriptive elements (one positive and one negative), which constitute "the essential structure of the riddle". According to Taylor, the positive element has a metaphorical nature in terms of the answer and is perceived by the listener in a literal sense. In contrast, the negative descriptive element is correctly interpreted literally. Thus, in the following example given by Taylor (1951: 94) "Something has eyes and cannot see" (Irish potatoes), the positive descriptive element "eyes" is metaphorical in terms of the answer "potato", while the negative descriptive element "cannot see" is literal. According to the author, the riddle solution is implied by the details of the positive descriptive element, whose interpretation misleads the listener because of his/her wrong perception of the figurative description as a literal one. This allowed Taylor to define the riddle as the one consisting of two descriptions of an object: one literal and one figurative, which confuses the recipient "who endeavors to identify an object described in conflicting ways" (Taylor 1943: 130).

At the same time, some scholars (Georges and Dundes 1963: 112, Eugenio 1982: xxiv) indicated certain ambiguity and inconsistency of the stated above point of view on the riddle structure since it does not apply to many of the texts in the most comprehensive collection of English riddles (Taylor 1951). To support this statement Georges and Dundes provide examples of riddles, having:

1. neither positive nor negative descriptive element: "My fader have a horse, Go everywhere he like" (pumpkin vine) (Taylor 1951: 142); "What goes all down street and comes back home, and sits in the corner and waits for a bone?" (shoe) (ibid.: 151);

2. no metaphors, consisting only of a literal description: What live in de river? (fish) (ibid.: 40); Red outside / white inside (apple) (ibid.: 625); 
3. both positive and negative elements, but the positive element is not metaphorical, e.g.: What goes to the branch and drinks and don't drink? (cow and bell) (ibid.: 85);

4. both positive and negative elements are metaphorical, e.g.: I know something got hand and don't wash its face (clock) (ibid.: 98).

Considering this, Georges and Dundes make a rational conclusion that "the best way to arrive at a definition of the riddle is through structural analysis, since definitions, based on content and style, have proved to be inadequate" (Georges and Dundes 1963: 113). Therefore, they believe it appropriate to delineate, first of all, a minimum unit of the riddle structural analysis. Following the ideas expressed by Petsch (1899) and Taylor (1943: 130), they use the term "the descriptive element" that consists of "a topic" and "a comment". "The topic" is the apparent referent, i.e. the object or item which is allegedly described in the riddle. "The comment" gives the additional information about the topic, mostly about its form, function or action of the topic, etc. Proceeding from these ideas, the authors propose a general structural definition of the riddle as "a traditional verbal expression that contains one or more descriptive elements, a pair of which may be in opposition; the referent of the elements is to be guessed" (Georges and Dundes 1963: 113). The views presented in this and other works (Abrahams 1968: 151, de Caro, 1986: 177, Green and Pepicello 1979: 18) are important for our analysis since they allow us to consider the riddle as the text composed of one or more descriptive elements, which comprise "the topic", or referent, and "the commentary".

In other words, the results of the carried out analysis of theoretical and practical papers give us sufficient grounds to view the so-called descriptive element as a structural component of a folk riddle, consisting of two plot elements termed, respectively, "the topic" and "the commentary", being the members of the second hierarchical level of the riddle composition.

We must also pay attention to another feature of the riddle structure, repeatedly indicated by a number of scholars (Green and Pepicello 1979: 15, Köngäs-Maranda 1971b: 54). This structural component of a riddle directly relates to the recipient's thinking activities. It is the riddle answer, or solution, defined as its specific structural element occurring in the listener's mind. Therefore, taking into account the suggested idea about the riddle's division into two parts reproduced by different people as its distinctive feature, within the framework of the undertaken description of the riddle structure we come to the necessity to consider the riddle solution as its indispensable structural component.

Thus, on the basis of the performed analysis we have synthesized a generalized scheme of the folk riddle structure and its plot elements, presented in Fig. 1.

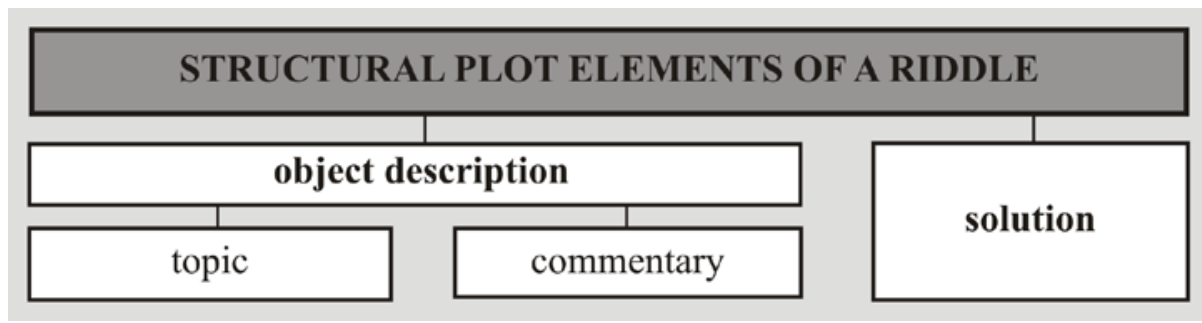

Figure 1: A generalized scheme of a riddle structure according to its plot elements 
The summarized scheme of the structural composition of English folk riddles allows us to use it as a logical guide for a further substantiation of the cognitive model representing a creative mechanism of riddle decoding by the recipient as well as for the auditory analysis of English folk riddles' prosodic organization.

\section{The analysis of a cognitive mechanism of a riddle decoding}

As it was shown above, a characteristic feature of a riddle is its division into two parts, reproduced by different individuals: the riddle content and its solution that occurs in the recipient's mind as a result of his/her mental activities. Therefore, it seems expedient to search for a cognitive model, representing a creative mechanism of riddle decoding, in direct correlation with the riddle structural composition.

We shall begin the study of this issue with an interesting idea suggested by de Caro (1986: 177-178) that a structural analysis can identify basic elements constituting the riddle as a whole and determine the way they relate to each other. He emphasized that the study of a riddle is not the matter of the analysis of its surface elements. The researcher has to consider the deeper levels of the text of a riddle and carefully examine examples of riddles, while making abstract generalization.

This proves an objective necessity of defining deep cognitive structures of the recipient's creative thinking activities, which under the influence of the riddle metaphoric content and its prosodic organization get involved into the riddle decoding. This idea is supported by a number of scholars (Boryslawski 2004: 24, Tucker 2011: 140) who also state that the world picture represented in the riddle answer, or solution, should coincide with the one encoded in the text of a riddle.

Taking into account the fact that the riddle contains an allusion and a metaphoric world representation to be decoded by the recipient (Sedakova and Tolstoy 1999: 233), it is not difficult to presume the complexity of the processes occurring in the recipient's mind.

To understand the specificity of a cognitive creative mechanism functioning in the recipient's mind it is important to be aware of the discursive nature of the riddle, inherent in its structure, which presupposes a dialogue, or communicative interaction (Butov 2011: 129). This once again demonstrates the feasibility of the chosen methodological approach aimed at substantiating the model of the riddle decoding by the recipient.

Herewith we would like to point to the methodology for the conceptual modelling of the riddle denotate, advanced by Selivanova (2000: 109-152). This methodology is grounded on the maxim that the mechanisms of human consciousness activities are triggered as a result of receiving information from the outer world. In view of this, the author emphasizes that the search for a riddle solution is a complex procedure that involves a psycho-cognitive mechanism, based on the riddle semiotic structure and the recipient's knowledge of the denotate, or referent. This mechanism comprises the interpretation of literal information stated in the riddle, reinterpretation of the riddle metaphorical scenarios from the standpoint of cultural stereotypes and archetypes, and processing of information underlying a paradoxical syntactic structure of a riddle (Selivanova 2005: 360). 
As methodological grounds for our modelling of the cognitive mechanism we also used the conceptual idea, put forward by Klimenjuk (2010: 205-234), that the recipient's speaking and thinking activities occur on four levels of his/her spiritual being: consciousness as well as transcendental, mental and existential spheres. Besides, according to Klimenjuk (ibid.: 225), thinking activities are understood as a set of interrelated processes of a poly-conceptual selfdeveloping emotional chaos, whose structuring and results of development are governed by a bi-conceptual consciousness. We also considered Z. Freud's postulate that transcendental and mental beings of a person unfold in the subconscious sphere, while existential being takes place in the unconscious one.

Therefore, in the further explanation of the model we used the following understanding (ibid.: 207) of basic notions and ideas. We understand the term "existential" as everything that relates to the unique originality within the human being, the person's feeling of belonging to the highest being, and which cannot be expressed in verbal concepts. We also believe that the existential life, which takes place in the unconscious sphere, is based on the emotional type of thinking and is mainly excited by prosodic means of the utterance. The occurrence of existential processes should be treated as the emotional type of thinking.

- The term "mental" refers to the result of the interaction between deep levels of a collective and individual consciousness, which determine the way of the individual's thinking and feelings, based on the unconscious regulations, as well as on the person's emotional and behavioral skills acquired due to perception and cognition of the outer world. We are to remark here that the human being's mental life, which unfolds in his/her subconscious, is based on the emo-rational type of thinking.

- The term "transcendent" denotes an act, process, or any product of the person's thinking about the fullness of his/her life or its individual characteristics that are considered inaccessible by direct knowledge, though can be perceived speculatively and expressed by abstract concepts. We shall follow the idea that the transcendent human existence, which takes place in his/her subconscious sphere, is based on the rational type of thinking.

- Thus, it becomes clear that within the human subconscious there occur mental and transcendental acts, whose common feature is the presence of elements of the rational type of thinking. Secondly, the motive power that generates the self-development of all thinking acts and processes, occurring in the individual's consciousness, is the psychophysiological energy of his/her personality. Thirdly, the human consciousness cannot control processes taking place in the human being's existential sphere. However, the consciousness can partially control the overall flow of mental and transcendent processes and thoroughly control the results of the joint activities of all the spheres of the individual's unconscious and subconscious beings. Fourthly, as it is also stated in the work by Klimenjuk (2010: 220), while modelling the cognitive processes of the riddle decoding it is efficient to confine ourselves to the use of the notions "emotional", "emo-rational", "rational", and "logical" concepts, determined by differences in the nature of their generation in the mentioned above spiritual spheres of human existence. 
These theoretical foundations made it possible to form a cognitive-and-creative model, representing a mechanism of riddle decoding by the recipient, whose graphical interpretation is shown in Fig. 2.

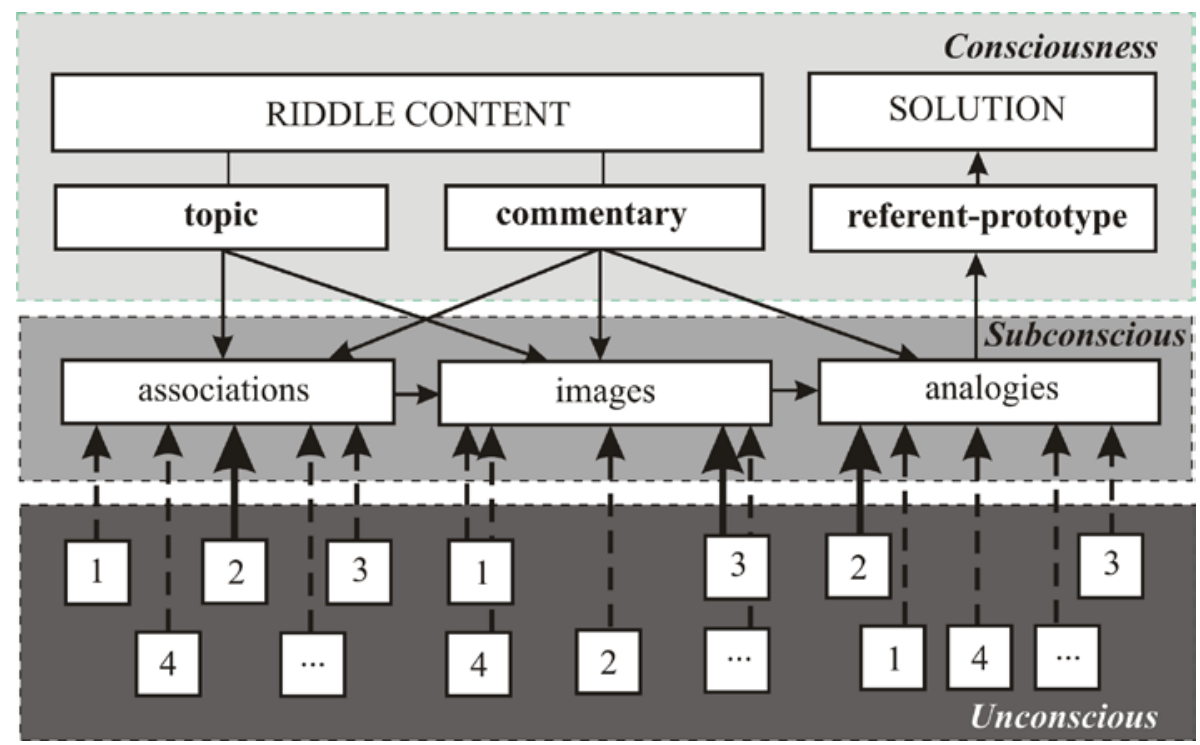

Figure 2: A cognitive-and-creative model of riddle decoding by the recipient

As it is seen from the scheme, the recipient's consciousness perceives all the substantiated above structural elements of the riddle (see. Fig. 1): topic $\rightarrow$ commentary $\rightarrow$ referentprototype.

Taking into consideration the mentioned ideas and postulates as well as the graphical image of the model, we can present the process of the recipient's riddle decoding as the sequence of the following steps. We presume, first of all, that the content of a riddle, being broadcast by the recipient's brain into the subconscious, stimulates a cognitive associative mechanism of his/her thinking. Under such conditions, there occurs the reinterpretation of a riddle as a complex concept that exists in the recipient's consciousness and is embodied in language units which are transformed by his psychophysiological energy into different by their nature units (associations, images, analogies).

The driving force of the mechanism realizing cognitive associative processes as a set of thinking acts is the psychic energy of the recipient's unconscious, which sends into his/her subconscious sphere the competing energy flows inherent to emotional concepts (marked in Fig. 2 as 1, 2, 3, 4...), excited by the riddle content.

Because of this emotional-and-energetic conflict, the energetically most powerful emotional concept (pointed in Fig. 2 by a highlighted arrow) acquires the status of a basic element of the association. Being fixed by the individual's consciousness, this association serves as an additional semantic element that triggers the search for a suitable image in the recipient's mental sphere.

The image, formed as a result of the mentioned process, carries a hypothetical intuitive information that triggers the final mental operation in the search for a riddle solution - the search for analogies. As a result, the most powerful concept, rising to the level of the subconscious, serves as a basis for the emergence of analogy, according to which the referent 
prototype is formed in the recipient's consciousness and then is transformed into the riddle solution.

We believe that the advanced model of a cognitive creative mechanism of riddle decoding can serve as a methodological basis for further studies of riddle oral actualization as well as can help explain the specificity of the riddle prosodic organization.

\section{Prosodic characteristics of the riddle structural elements}

Considering the ideas and postulates outlined above, we performed the auditory analysis of 227 English folk riddles (Bryant 2007: 92-109), aimed at defining a set of prosodic means differentiating the riddle structural elements "the topic" and "the commentary" as well as activating in the recipient's consciousness a cognitive-and-creative mechanism of riddle decoding.

The result of the auditory analysis revealed that the riddle structural element "the topic", which contains an indirect reference to the object described in the riddle, is characterized by the predominant use of neutral parameters of intonation: moderate tempo and loudness, a rising kinetic tone in the non-terminal intonation group and a falling tone in the final one, mid voice range, wavy-like pitch contour, low pitch levels of its beginning and end, for example: If you Ifeed it $\xi$ it will live... (ibid.: 94).

At the same time, an introduction of the riddle object can be marked by a mid-high pitch in cases when "the topic" begins with a notional stressed word (e.g.: Lives with out a body, | Ihears with'out ears), or with a rising pre-head when the head is preceded by several unstressed syllables (e.g., There is a ‘ity...) (ibid.: 102).

Enumeration of several features of the described object within the structural element "the topic" is usually accompanied by the alternation of different pitch levels of high-rising tones, for example: It was Ineither 'fish, \{lflesh, \}nor bone... (ibid.: 97). However, as is seen from the example, the final feature of the described object is marked by the low falling terminal tone. Such an intonation model is usually used for enumeration in emotionally neutral speech and serves, at the same time, as an indicator of the low level of emotional potential of the riddle structural element "the topic".

A gradual increase in the emotional potential of "the topic" in the direction to a high zone of the low level is achieved by the combination of two low-falling terminal tones in the adjacent intonation groups (e.g., IEast and west $\xi$ and Inorth and south (Bryant 2007: 92) as opposed to the described above combination of rising and falling tones, characteristic of a consistently low level of "the topic" emotional potential. A slight increase in the emotional potential of this structural element is also indicated by: (1) the presence of a broken descending stepping head within its intonation groups (e.g., When'I was 'young and beautiful | I 'wore a $\uparrow$ blue crown... (ibid.: 105), (2) actualization of a high-falling terminal tone of a wide range and convex configuration within its initial intonation group (e.g., My fatherland $\xi$ is A rabia... (ibid.: 92) . ...... . l), and (3) the use of a falling tone consisting of an ascending tone direction on its stressed element followed by a low level tone of the unstressed tail (e.g.,

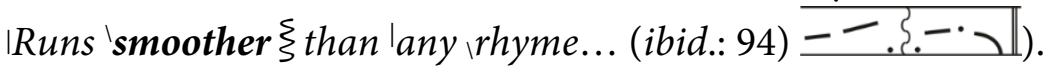


The presence of the mentioned prosodic means within the structural element "the topic" contributes, as a rule, to attracting the listener's attention to those features of a described object, which will contrast to its characteristics, given in the structural element "the commentary" and will serve as a key for the creation of the metaphorical image in the listener's mind, necessary to continue search for associations and analogies of the riddle solution.

Prosodic organization of "the commentary" differs from "the topic" since it contains the rheme of a riddle and, consequently, is marked by emphatic prosodic means aimed at the rheme intensification. Besides, the use of emphatic prosodic parameters is conditioned by the function of "the commentary", which is to highlight specific features of the described object or give additional information about it. In other words, prosodic organization of "the commentary" serves to intensify those lexical units which are to excite in the recipient's psyche images and associations as well as trigger the search for analogies in the process of riddle decoding.

Thus, the typical features of "the commentary" prosodic organization include: (1) the combination of two falling kinetic tones of different pitch within a single intonation group, e.g.: ... and 'wasn't a beast... (ibid.: 97); And I'm the 'torment of \man (ibid.: 106), the higher of which serves to highlight a specific feature of a described object, marked by the low falling tone; (2) the use of emphatic heads: sliding and stepping broken heads, e.g.ì Couldn't put

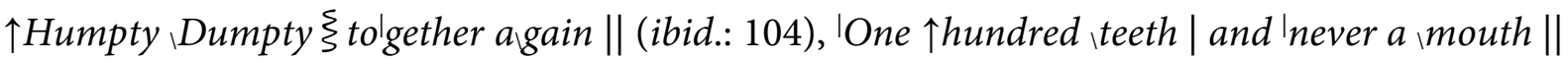
(ibid.: 104), whose function in riddles, unlike narrative folk texts, is not to eliminate the speech monotony, but intensify key lexical units which are to launch the image search in the recipient's psychic sphere as a basis of the referent prototype. A similar function is performed by high falling terminal tones in adjacent intonation groups, the latter having a slower rate of

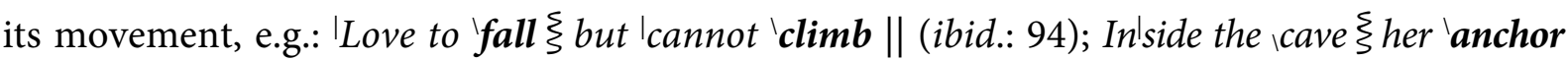
|drops || (ibid.: 102).

Differential features of "the commentary" prosodic organization comprise the slowed down tempo of its final intonation group and perceptual pauses $(\xi)$ that emphasize the rhematic element of a riddle, for example:

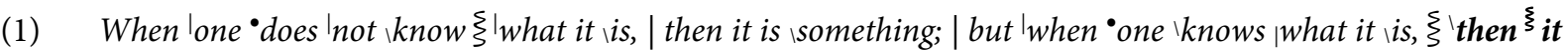
is nothing || (ibid.: 102);

(2) $\quad$ Lives in'winter, $\xi \mid$ dies in $\$ summer, | and $\mid$ grows with its /roots ${ }^{\xi} \mid$ upwards $\|$ (ibid.: 99).

The rhematic element of the riddle can also be highlighted by the preceding tone interval, as in the example: ... and 'when he ${ }^{-f i n d s}$ vwater, | ${ }^{-}$he perishes || (ibid.: 102), where the word perishes is intensified by means of a negative mid tone interval at the juncture of a preterminal part and a nucleus.

Given the fact that an oral actualization of the riddle as a genre presupposes engaging the recipient into creative thinking processes aimed at enhancing in the entertaining form his/her cognitive abilities, the speaker usually tries to produce the riddle in an "enigmatic" voice coloring to which the listener responds in the first place. The auditory analysis has shown that 
such a coloring of voice is characteristic of the final intonation group of "the commentary" which is qualified as a pragmatically most important component of the text of a riddle. So there is every reason to conclude that riddle's pragmatic potential is constantly growing, reaching its maximal mid-high level within the final intonation group. In the following example of the final intonation group of "the commentary" ...'What is it? || (ibid.: 105) the pragmatic loading is increasing due to the combination of its "enigmatic' voice coloring, the use of a high falling tone of a wide range ('What...) and a negative mid tone interval at the juncture "nucleus-tail". It was also defined that timbre can acquire a leading role in highlighting the final intonation group of a riddle in cases when it is combined with the slowed-down tempo and a low falling terminal tone with a reduced rate of its movement, e.g.: The |foot trod on it | and the |mouth enjoyed it || (ibid.: 107). The outlined interaction of prosodic parameters should be viewed as the subliminal means of involving the listener into the process of riddle decoding.

The auditory analysis also allowed us to conclude that the riddle's structural elements are singled out, as a rule, with the help of a medium-length pause while the intonation groups occurring within these elements are separated by a short pause, e.g.:

'Cut me 'up in pieces $\xi$ and 'bury me allive, |

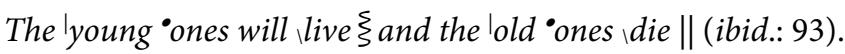

Apparently, the presence of short pauses between intonation groups that are used within structural elements and medium-length pauses at their junctures is the invariant feature of English folk riddles' prosodic actualization.

Prosodic organization of a riddle has also differential features which are the result of the speaker's appraisal of the riddle referent, which causes a corresponding change in his/her emotional state while pronouncing the riddle out loud. The following riddle about the coffin as its referent can serve as an example:

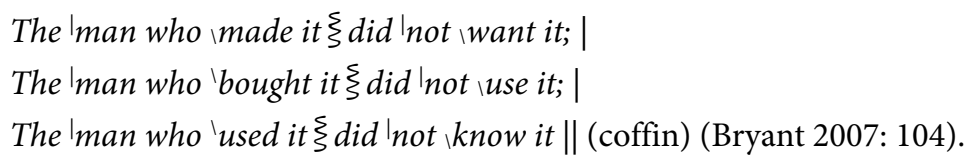

The emotional component of this example, generated by the ethical appraisal of the described referent as well as the corresponding change in the speaker's emotional state, is realized by the speaker's use of a parallel intonation patterns of both structural elements, alternation of falling tones' pitch of all verbs of the riddle, the use of a negative tone interval at the juncture "nucleus-tail" (e.g.: 'bought it). Such prosodic specificity serves to attract the recipient's attention to each verb, thus increasing the riddle pragmatic loading.

The negative ethical evaluation of the riddle referent can be enhanced by segmental means against the background of intonational parallelism of adjacent intonation groups, in particular by alliteration, assonance, and repetition of sound combinations, for example:

|Brass' cap and 'wooden, head, |

|Spits fire乡 and |spews \lead || (gun) (ibid.: 98). 
In this example, the metaphorical image of a gun is created, along with the described above specific intonation, by the repetition of sound combinations $b r$-, sp- which are traditionally viewed as unpleasant ones or as those which produce a negative aesthetic impact on the listener.

We believe that the appearance within the riddle of similar or identical sounds and sound combinations enhances the semantic loading of some lexical units, thus inducing the appearance in the recipient's mind of corresponding associations related to the general emotional tone of the riddle. Thus, we can conclude that the interaction of segmental and suprasegmental means organizing the riddle is caused by a definite semantics of its referent, which, in its turn, can help the recipient find a correct riddle solution.

The results of the conducted auditory analysis showed that the invariant prosodic pattern of the riddle oral actualization, which ensures the excitement of the recipient's creative associative mechanism of the search for its answer, comprises the following parameters of intonation: division of the text into short intonation groups, the use of rising pre-heads, checked or broken descending stepping heads, falling tones, wave-like pitch contour, regular rhythm, short pauses within structural elements and mid ones at their junctures. Invariant features of the riddle also include an emphatic prosodic organization of its final intonation group, which, being the riddle's semantic and pragmatic center, performs a subliminal function and excites the recipient's imagination and stimulates him/her to find the riddle answer.

\section{Conclusions}

The advanced in the paper methodological guidelines and the results of the auditory analysis of English folk riddles allowed us to outline characteristic features of their prosodic organization as well as substantiate invariant and differential prosodic means typical of the riddle structural elements.

The suggested model of a cognitive creative mechanism of riddle decoding proves that the content of a riddle, being broadcast by the recipient's brain into the subconscious, stimulates a cognitive associative mechanism of his/her thinking that comprises the reinterpretation of a riddle as a complex concept embodied in language units which are transformed by the recipient's psychophysiological energy into associations, images, and analogies as the bases of the riddle referent-prototype.

The carried out auditory analysis of English folk riddles confirmed that the riddle prosodic organization aims at highlighting those lexical units which realize a subliminal influence on the recipient's subconscious providing the stimulus for his/her search for images, associations and analogies in the process of riddle solution decoding.

We believe that the suggested approach to modelling a cognitive creative mechanism of a riddle decoding and the analysis of prosodic specificity of its oral actualization can serve as methodological guidelines for further studies of speech decoding phenomena. 


\section{References}

Aarne, A. 1961. The Types of the Folktale: a Classification and Bibliography. Translated and enlarged by S. Thompson. Helsinki: Academia Scientarum Fennica.

Abrahams, R.D. 1968. Introductory Remarks to a Rhetorical Theory of Folklore. The Journal of American Folklore 81, 320: 143-158.

Abrahams, R.D., and A. Dundes. 1982. Riddles. In R.M. Dorson (ed.), Folklore and Folklife: An Introduction, 129143. Chicago: University of Chicago Press.

Alefirenko, N.F., and N.N. Semenenko. 2010. "Znachenie i smysl russkih paremij v svete kognitivnoj pragmatiki" ["The meaning and sense of Russian proverbs and sayings in the light of cognitive pragmatics"] Izvestija Ural'skogo gosudarstvennogo universiteta. Serija 1: Problemy obrazovanija, nauki i kul'tury [Newsletter of Ural State university. Series 1: The problems of education, science, and culture] 6(85): 169-180. (in Russian)

Anikin, V. 1957. Russkie narodnye poslovicy, pogovorki, zagadki i detskij fol'klor [Russian folk proverbs, sayings, riddles and children folklore]. Moscow: Uchpedgiz. (in Russian)

Aristotle, 2000. Ritorika. Pojetika [Rhetoric. Poetics]. Moscow: Labirint. (in Russian)

Beuchat, P.D. 1965. Riddles in Bantu. In A. Dundes (ed.), The study of Folklore, 182-215. Englewood Cliffs: Prentice-Hall.

Boryslawski, R. 2004. The Old English Riddles and the Riddle Elements of Old English Poetry. Frankfurt am Main, Berlin, Bern, Wien: Lang.

Bryant, M. 2007. Riddles Ancient and Modern. London: Hutchinson.

Butov, O.V. 2011. Problema definicii' zagadky [The problem of the riddle definition]. Visnyk Cherkas'kogo universytetu. Serija: Filologichni nauky [Messenger of Cherkassy university. Series: Philological studies] 213: 125-130. (in Ukrainian)

Caro de, F.A. 1986. Riddles and Proverbs. In E. Oring (ed.), Folk Groups and Folklore Genres: An introduction, 175-197. Logan: Utah State University Press.

Dundes, A. 1975. On the Structure of the Proverb. In A. Dundes (ed.), Analytic essays in folklore, 103-118. The Hague: Mouton.

Eugenio, D.L. 1982. Philippine Folk Literature: An Anthology. Philippine Folk Literature Series. Diliman, Quezon City: Folklore Studies Program, College of Arts \& Sciences, University of the Philippines, The U.P. Folklorists, Inc.

Fylyppov, V.S. 2000. Kommunikativnaja priroda zagadki [The riddle communicative nature]. PhD diss., Orol University, Russia. (in Russian)

Georges, R., and A. Dundes. 1963. Toward a Structural Definition of the Riddle. The Journal of American Folklore 76, 300: 111-118.

Gimbutas, Ž. 2004. The Riddle in the Poem. Lanham, Maryland: University Press of America.

Green, T., and W.J. Pepicello. 1979. The Folk Riddle: A Redefinition of Terms. Western Folklore. 38(1): 3-20.

Green, T., and W.J. Pepicello. 1980. Sight and Spelling Riddles. Journal of American Folklore 93, 367: 23-34.

Green, T., and W.J. Pepicello. 1986. The Proverb and Riddle as Folk Enthymemes. Proverbium 3: 33-45.

Ivanov, V.V., and V.N. Toporov. 1975. Invariant i transformacii v mifologicheskih i fol'klornyh tekstah [Invariant and transformations in mythological and folklore texts]. In E.M. Meletinskij, and S. Ju. Nekljudov (eds.), Tipologicheskie issledovanija po fol'kloru: [sb. st. pamjati Vladimira Jakovlevicha Proppa (1895-1970) [Typological studies of folklore: collection of papers in memory of Vladimir Propp (1895-1970)], 44-76. Moscow: Nauka. (in Russian)

Kaivola-Bregenhøj, A., and Th. du Bois. 2001. Riddles: Perspectives on the Use, Function and Change in a Folklore Genre. Helsinki: Finnish Literature Society.

Klimenjuk, A. 2010. Znanije, poznanije, kognitsija [Knowledge, learning, cognition]. Ternopol: Textbooks. (in Russian)

Köngäs-Maranda, E. 1971. The Logic of Riddles. In Structural Analysis of Oral Tradition, 189-232. Philadelphia: University of Pennsylvania Press.

Köngäs-Maranda, E. 1971b. Theory and Practice of Riddle Analysis. The Journal of American Folklore. 84, 331: 51-61. 
Levin, Ju.I. 1973. Semanticheskaja struktura russkoj zagadki [Semantic structure of the Russian riddle]. Uchenye zapiski Tartuskogo gosudarstvennogo universiteta. Trudy po znakovym sistemam VI: sb. nauch. statej $v$ chest' Mihaila Mihajlovicha Bahtina ( $k$ 75-letiju so dnja rozhdenija) [Scientific notes of Tartu state university. Papers on semiotic systems VI: collection of papers to honor Michael Bakhtin (to his $75^{\text {th }}$ birthday)] 306: 166190. (in Russian)

Lotman, J. 1992. Izbrannye stat'i v 3 t. Stat'i po semiotike i tipologii kul'tury [Selected works in 3 volumes. Papers in semiotics and typology of culture. Vol. 1]. Tallinn: Aleksandra press. (in Russian)

Panasenko, T. 2009. Kroskul'turni zv'jazky zagadok riznyh narodiv [Cross-cultural connections of different peoples' riddles]. Naukovi zapysky Kirovograds'kogo DPU imeni V. Vynnychenka. Serija: Filologichni nauky (Movoznavstvo) [Scientific notes of V.Vynnychenko Kirovograd state university. Series: Philological Studies (Linguistics)] 81(3): 381-385. (in Ukrainian)

Permyakov, G.L. 1975. K voprosu o strukture paremiologicheskogo fonda [Towards the question of paremiological fund]. In E.M. Meletinskij, and S. Ju. Nekljudov (eds.), Tipologicheskie issledovanija po fol'kloru: cb. st. pamjati Vladimira Jakovlevicha Proppa (1895-1970) [Typological studies of folklore: collection of papers in memory of Vladimir Propp (1895-1970)], 247-274. Moscow: Nauka. (in Russian)

Petsch, R. 1899. Neue Beträge zur Kenntnis des Volksrätsels. Berlin: Meyer und Müller.

Sedakova, I.A., and S.M. Tolstoy. 1999. Zagadka [The riddle]. In N.I. Tolstoy (ed.), Slavjanskie drevnosti: jetnolingvisticheskij slovar': v 5 t. [Slavonic antiquities: ethnolinguistic dictionary in 5 volumes], 2: 233-237. Moscow: International relations publishing. (in Russian)

Selivanova, E. 2000. Kognitivnaja onomasiologija [Cognitive onomasiology]. Kyiv: Phitosociocentre. (in Russian)

Selivanova, E. 2005. Kognitivnye mehanizmy denotacii ukrainskoj zagadki [Cognitive mechanisms of the Ukrainian riddle denotation]. Uchenye zapiski Tavricheskogo nacional'nogo universiteta im. V. Vernadskogo. Serija: Filologija [Scientific notes of V. Vernadskij Tavriya national university. Series: Philology] 18(57), 2: 356-360. (in Russian)

Semenenko, N.N. 2011. Problema opisanija funkcional'no-kategorial'nogo statusa zagadok kak paremicheskogo zhanra [The problem of describing a functional and categorical status of riddles as a paremeological genre]. Izvestija Rossijskogo gosudarstvennogo pedagogicheskogo universiteta im. A.I. Gercena [Newsletter of A. Gertsen Rostov state pedagogical university] 127: 129-136. (in Russian)

Taranenko, L. 2013. Fabul'na structura folklornoyi zagadky ta kognityvno-kreativnyi mekhanizm yiyi decoduvan'y [The plot structure of the folk riddle and the cognitive-and-creative mechanism of it decoding] Science and Education a New Dimension: Philology, Budapest, I (3), 13: 167-174. (in Ukrainian)

Taylor, A. 1943. The Riddle. California Folklore Quarterly. 2(2): 129-147.

Taylor, A. 1951. English Riddles from Oral Tradition. Berkeley, Los Angeles: University of California Press.

Thompson, S. 1955. Motif Index of Folk-literature: a classification of narrative elements in folktales, ballads, myths, fables, mediaeval romances, exempla, fabliaux, jest-books, and local legends. Bloomington, IN: Indiana University Press.

Tucker, B. 2011. Reading Riddles: Rhetorics of Obscurity from Romanticism to Freud. Lewisburg, Pa: Bucknell University Press.

Tupper, F. Jr. 1910. Introduction. In F. Tupper, Jr. (ed.), The Riddles of the Exeter Book. Boston: Ginn \& Co. 